21 См. более подробно об этом в ранее указанной статье О. Звейниекса.

22 Ведомости. - 1990 . - № 20.

23 Zinotäjs. - 1994. - Nr. 23.

24 Zinotajss. - 1995. - Nr. 12.

$2 s$ Zinotajjs. - 1994. - Nr. 11.

26 Zinotajjs. - 1995. - Nr. 11.

27 Bojars J. Nepielausim Latvijas nacionalas bagatibas izlaupiłanu//Neatkariga Cina. -1995 . -1 junijs.

28 См. Федоров П. Морские границы. Для чего они нужны?//Диена.-1994. 11 июля.

г. Рига

Статья поступила в редакцию 10 октября 19972.

\title{
РЕАЛИЗАЦИЯ ПРИНЦИПА САМООПРЕДЕЛЕНИЯ НАЩИЙ И НАРОДОВ В ЭФИОПИИ И ОБРАЗОВАНИЕ ГОСУДАРСТВА ЭРИТРЕЯ
}

\author{
Лемма Хома Коч $\mathrm{e}^{*}$
}

. Теоретическая разработка принципа самоопределения наций и народов привлекала внимание многих ученых России и зарубежных стран.

Идея принципа самоопределения наций и народов возникла еще в XVII-XVIII веках. Tогда формулировка этого принципа была понятна: "одна нация - одно государство". Принцип национальности нашел свое отражение в ряде документов в период Великой французской революции. Аббат Грегуар предложил конвенту проект декларации международного права, в котором говорилось: “Народы по отношению друг к другу независимы и суверенны, кахово бы ни было холичество составляющих нх лиц и размер занимаемой ими территории"' Данный принцип может иметь разные интерпретации в зависимости от стадни общественного развития или мировой политики. То, что является ахтуальным на одном историческом этапе, не остается неизменным. Изменения обшественных условий могут трансформировать взгляды на соответствующие явления, и это потребует изменений ранее принятых определений. Например, отождествление нации и государства нередко встречается в трудах ученых как старшего поколения, так и нынешнего. В монографической работе швейцарца Эмера де Вателя, юриста - специалиста в области международного права XVIII века, читаем: "Всякая нация, которая самоуправляет собою, в какой бы это форме ни осуществлялось, без какой-либо иностранной зависимости представляет собой суверенное государство"'.

\footnotetext{
* Аспирант из Эфиопии. Кафедра государственного и международного права Казансхого государственного университета.
} 
Многие специалисты солндарны в том, что нация характеризуется обшностью территории, языка, экономических связей, психического склада, культуры и самосознания ${ }^{3}$. Однако в мировой практике образования государств нередко наблюдается, когда государство состоит из нескольких народностей или национальных групп. Это не означает, что каждая нация должна образовать государственность на основе принципа национальности.

В конце XVIII века с развитием общества принцип национальности "одна нация - одно государство" потерял свою ахтуальность. Принцип национальности, сформулированный в эпоху восходящего развития капитализма, охазался непригодным... Принцип национальности разъединил пролетариев различных наций. Для решения национально-колониального вопроса необходима была иная основа. Такой основой в новых исторических условиях явился принцип самоопределения наций и народов. На конференции в Сан-Франциско в 1945 году делегация Советского Союза предлагала включить в Устав ООН принцип самоопределения народов и наций. Таким образом, принцип самоопределения наций и народов заменил принцип национальностин.

Благодаря принципу самоопределения наций и народов огромное количество стран мира получили свою независимость. Теории, разработанные учеными мира, обогащаются и подкрепляются мировой практикой. $\mathrm{K}$ такой практике можно отнести независимость Эритреи, которая получила мировое признание в начале 1990-х годов. Поэтому необходимо рассмотреть процесс реализации данного принципа в Эфиопии и образование государства Эритрея.

Исторические факторы, возникновение вооруженной борьбы, изменение политической обстановки, демократические процедуры, волеизъявление народа и образование государства Эритрея, а также роль международных организаций и некоторые другие являются аспектами, заслуживающими внимания, и освешены в настоящей работе.

Вооруженная борьба между Эфиопией и Эритреей явилась самой длительной борьбой за независимость в Африке и одной из мировых кампаний за самоопределение, в которые была вовлечена Организация Объединенных Наций'. Как внутри страны, так и за рубежом многие считали борьбу за независимость Эритреи неправомерной. Такую позицию можно объяснить несколькими причинами: 1) незнанием исторического факта; 2) искажением толкования принципа самоопределения нации и народов; 3) игнорированием требований народов.

Для объективного решения национального вопроса Эритреи играет огромную роль знание исторических фактов. Необходимо знать корни конфликтов и первопричину постановки вопроса.

На захате феодальной раздробленности шла борьба между правителями разных народов. Позднее целями объединения явились: 1) сосредоточение власти в руках одного императора и подчинение ему остальных правителей разных народов; 2) совместная борьба и зашита территории современной Эфиопии от иностранных держав. Борьба за сосредоточение власти в руках императора шла во второй половине XIX века, и фактически политика сосредоточения власти в одних руках продолжалась до конца царствования императора Хайле Селассие I. А. Бартницкий и Мантель Нечко справедли- 
во дали следуюшую характеристику данному событию: “Объединение Эфиопии шло военным путем. Теорос II оружием заставлял отдельных феодалов подчиниться императорской власти. Подчинив страну силой оружия и задушив наиболее острые проявления сепаратизма, император пытался с помощью репрессий сохранить политическое единство государства"6.

Международная обстановка второй половины XIX века требовала консолидации раздробленной Эфиопии. Необходимо было объединиться и совместно бороться против общих врагов - европейских колонизаторов, в том числе и против Италии. Победа под Адуа над Италией убедила народы Эфиопии в необходимости консолидации и укрепила единство Эфиопии.

Однако после победы под Адуа и уменьшения протяженности границы, идущей по рекам Мэреба, Долеса и Нуны, будущим поколениям остались отчужденные территории Эфиопии, которые надо было возвращать путем военных конфликтов. Сначала на основе Уччилийского договора между Мениликом и Италией 1889 года, затем после победы под Адуа мирным договором 1896 года была установлена граница от побережья моря. Современная Эритрея оставалась колонией Италии до 1941 года'. После освобождения Эритреи от итальянской колонизации в 1941 году великие державы (Франция, Советский Союз, Соединенное Королевство и США) решиши, что Эритрея должна стать протекторатом Великобритании. $\mathrm{K}$ этому времени появилось пять политических организаций, четыре из которых поддерживали независимость Эритреи. К концу 1940-х годов вопрос о статусе Эритрен обсуждался на международном уровне в Нью-Йорке, и в декабре 1950 года Генеральная Ассамблея ООН приняла резолюцию 390/A/V об объединении Эритреи с Эфиопией на основе федерализма ${ }^{8}$.

Данная резолюция получила практическое воплошение в жизнь в 1952 году, когда впервые в истории Эритреи были проведены демократические выборы и когда создалась федерация Эритреи и Эфиопии. Ғосле ратификации федерального акта императором Хайле Селассие правление Великобритании подошло к концу9. В середине 1950-х годов возникла тревожная обстановка: обмен официальных языков (тыгрынья* и арабского) и объявление амхарского языка государственным, запрет отдельных флагов и, наконец, в 1962 году прекращение указом императора № 27 федерации Эритреи с Эфиопией. Статус автономии Эритреи изменился на провинциальный ${ }^{10}$. Такие меры императора Хайле Селассие вызвали недовольство народа. В связи с этим к началу $60-\mathrm{x}$ годов начал организовываться Фронт освобождения Эритреи (ФОЭ). Несмотря на существование некоторых различий между группами населения в религиозном отношении или по национальному происхождению, у него была одна цель. Таким образом, Фронт освобождения Эритреи и Народный фронт освобождения Эритреи (НФОЭ) продолжали вооруженную борьбу против двух режимов: до сентября 1974 года против монархии во главе с императором Хайле Селассие, а затем до 1991 года против военно-административного режима. Если для руководства Эфиопии важнейшим явилось сохранение территориальной целостности государства, то для освободительных движений - получение независимости.

* Тыгрынья - один из популярных языков Эритреи, на котором говорит большинство населения. 
Вооруженная борьба за независимость Эритреи стала наиболее острой при Менгисту Хайле Мариаме. Национальный вопрос в Эритрее приобрел острый характер и вызвал разногласия между наиболее известными обшественно-политическими группировками, в том числе между Эфиопской народно-революционной партией (ЭНРП) и Всеэфиопским социалистическим движением (ВЭСО), или МЭИСОН (на амхарском языке)"

Эфиопская народно-революционная партия поддерживала борьбу за независимость Эритреи. "Немедленное создание народного правительства!", “Демократия без ограничений!", “Самоопределение народов!” и другие лозунги использовала ЭНРП, но сторонники правительства заявили: “Мы против отделения... В Эфиопии нет условий и оснований для отделения национальностей! Мы - за реализацию региональной автономии!"'2

Основой раскола являлось искажение в толковании или интерпретации принципа самоопределения. Одни начисто отрицали положительную роль данного принципа, а другие не имели обших взглядов по вопросу о том, на кого он должен распространяться. В некоторых исследованиях упоминается о том, что западные юристы, такие как М. Померанс, Дж. М. Уйсдом, М. Сибер, отрицали его правовой характер и лишали его юридической силы. А другие юристы, такие как М. Делупи и И.Л. Грин, отождествляли самоопределение с сепаратизмом ${ }^{13}$.

По мнению Л.И. Воловой, самоопределение и сепаратизм разграничиваются по семи критериям. Согласно ее определению, сепаратизм - это выдвижение кахой-либо национальной или этнической группой требований об отделении, это деятельность, направленная на создание одной из наций или этнических групп самостоятельной государственности на национальной почве или этнической основе путем выхода из состава государства без учета каких-либо правовых оснований ${ }^{14}$. Таким образом, автор относила вооруженную борьбу за независимость Эритреи к сепаратизму's. Нельзя не согласиться с данным определением. Но трудно признать, что это было характерно для Эритреи. Во-первых, на данной территорин живут более восьми этнических групп, имеющих разные языки, вероисповедание, даже культуры ${ }^{16}$. Во-вторых, с 1890 по 1941 год Эритрея была оторвана от Эфиопии. В-третьих, после объединения с Эфиопией на началах федерализма император изменил статус автономии вопреки воле ее народа и лишил преимушеств, вытекаюших из этого статуса. Нельзя игнорировать эти факторы и не считать их правовыми основаниями.

Однако, с одной стороны, как на ранней стадии возникновения вопроса самоопределения Эритреи, так и на стадии его разрешения Эфиопия не признала Эритрею как субъект самоопределения, а с другой - Народный фронт освобождения Эритреи не хотел отступить от намеченной цели. Обе стороны отстанвали свою точку зрения и не могли прийти к компромиссу. Г.Б. Старушенхо, анализируя подобную ситуацию, подчеркивал, что "в современном мире без согласия государства нет конструктивного самоопределения" 17 .

Акцент делается на решаюшую роль государственной власти. Не отрицая роли государства, нельзя игнорировать роль народа, поскольку государство должно действовать от имени народа и защищать его интересы. Таким образом, можно прийти к выводу, что только согласие обеих сторон ведет к конструктивному самоопределению. 
Принцип самоопределения и принцип сохранения территориальной целостности государства взаимосвязаны. Поэтому согласование этих двух принципов ведет к объективному решению вопроса самоопределения. Существует мнение, что во время холодной войны мнровое сообщество не поддерживало отделения Эритреи по следуюшим причинам:

1) необходимость выхода $\mathbf{x}$ морю Эфиопии для сушествования этого государства;

2) политическая и экономическая несостоятельность самой Эритреи;

3) независимость Эритреи могла вызвать дезинтеграцию (распад) других африканских государств ${ }^{18}$.

Поэтому необходимо было рекомендовать иную форму реализации принципа самоопределения - предоставление особого статуса автономии и провозглашение некоторых аспектов ее реализации в хонституции страны. В этом направлении были сделаны некоторые шаги. Например, Конституция 1987 года гарантировала некоторые права. "Народно-Демократическая Эфиопия является унитарным государством, в котором все национальности живут на равных правах" (п. 1 ст. 2); "Народно-Демократическая Эфиопия гарантирует реализацию региональной автономии" (п. 4 ст. 2); "НародноДемократическая Эфиопия гарантирует равенство, развитие и уважение языков всех национальностей" (п. 5 ст. 2) и др. ${ }^{19}$

В соответствии с Конституцией 1987 года Эритрея была одной из территорий, имеющих особый статус в рамках унитарного государства. По сравнению с политическим статусом Эритреи в начале 1960-х годов, на наш взгляд, Конституция 1987 года - это шаг вперед. Однако это не удовлетворило требования Народного фронта освобождения Эритреи. Попьтки мирных переговоров в 1989 году в Атланте, в 1990 году в Найроби и в 1991 году в США были неудачными. Народный фронт освобождения Эритреи решительно требовал самоопределения, вплоть до отделения.

Принцип самоопределения сложен как в теории, так и на практике. Пока не нашлось универсального рецепта, которым руководствовались бы все народы, находящиеся на разных экономических и социально-экономических этапах развития. Если не обеспечивается соблюдение национальных и социальных прав народов на границах существующих государств и если государство допускает приобретение прав одним народом за счет ушемліения или игнорирования прав и интересов других, рано или поздно потребуется реализация данного принципа любым способом.

В.И. Ленин подчеркивал, что "надо решительно требовать права нации на самоопределение там, где имеются насильственные связи между нациями... не следует бояться отделения, так как оно в любом случае лучше, чем насильственное объединение вопреки воле народа" 20 .

В ходе реализации принципа самоопределения наций и народов приоритетным является волеизъявление не всего населения государства, а хоренного населения, проживающего на данной конкретной территории. В случае игнорирования мирного способа волеизъявления народа не исключается и иной способ реализации данного принципа, то есть вооруженная борьба. С.В. Черниченко отмечает: "Самый сложный вопрос - это выявление воли народа или нации. Эта воля народа может выявляться как мирным путем, так и в процессе вооруженной борьбы"'?. Эритрея пошла по второму пути. 
Вооруженная борьба Народного фронта освобождения Эритреи, Фронта освобождения Эритреи, Фронта освобождения Афара (ФОА), Демократической организации народа орома (ДОНО), Демократического движения народов Эфиопин (ДДНЭ) и других усилилась. В июне 1989 года организовался Революционно-демократический фронт эфиопских народов (РДФЭН), привлекший х себе несколько движений на основе коалиции. В результате жесточайшего экономического кризиса и повсеместной потери доверия народа, после серии вооруженных поражений в стране рухнул режим Менгисту Хайле Мариама.

Фактически Народный фронт освобождения Эритреи полностью контролировал столицу Эритреи два дня, после того как лидер Эфиопии Менгисту Хайле Мариам покинул страну. 27 мая было сформировано временное правительство Эритрен, и через день Революционно-демократический фронт эфиопских народов взял Аддис-Абебу под свой контроль ${ }^{22}$. Таким способом в Эритрее реализовался принцип самоопределения наций и народов. Для легализации достигнутой вооруженным путем цели необходимо было провести нехоторые демократические процедуры, получить мировое признание. Для этого временному правительству Эфиопии и Эритреи нужно было решить три важнейшие задачи:

1. В соответствии с последним соглашением мирных переговоров в США получить возможность участия в лондонских переговорах в хонце мая 1991 года.

2. Создать условия для многих политических организаций, которые подробно решают вопрос независимости Эритреи, обсуждают и принимают хартию временного правительства Эфиопии.

3. Организовать референдум в Эритрее.

Решение этих задач началось. 27 мая во время лондонских переговоров представители НФОЭ под похровительством США встретились с представителями временного правительства Эфиопии и пришли к соглашению о том, что временное правительство Эритреи должно организовать референдум в течение двух лет по вопросу независимости ${ }^{23}$. Нз коалицнонного временного правительства Эфиопии большинство фракции Фронта освобождения Тыграя (ФОТ) подлерживало независимость Эритреи ${ }^{24}$. С 1 по 5 июля 1991 г. в Аддис-Абебе состоялась Мирная и демократическая конферекция, В которой приняли участие многие политические организации и присутствовали некоторые межправительственные и международные организации, включая ООН, выступавшие в качестве наблюдателей. В этой конференции участвовали представители 22 национальностей, присутствовали наблюдатели ООН, ОАЭ, США, бывшего СССР, Великобритании, Германии, Швеции, Судана, Нигерии, Кении, Италии, Франции, Джибути, Канады, Китая, ветераны мирной комиссии аd hoc и журналисты ${ }^{23}$.

На хонференции также обсуждался вопрос отношений Эритреи с Эфиопией, была принята новая хартия и были достигнуты некоторые положительные результаты. В соответствии с достигнутыми соглашениями и обращениями лидеров временного правительства ОOH решила создать наблюдательную комиссию (UNOMVER*), состоявшую из 21 человека, для

*United Nations Observation Mission Verlifying the Eritrean Referendum. 
проверки справедливости, демократичности и правомочности референдума в Эритрее. Кроме того, дополнительные наблюдатели были направлены в разные пункты голосования за пределами Эритреи ${ }^{26} .7$ апреля 1993 г. временное правительство Эфнопии сдало прокламацию № 22/1992 о референдуме в Эритрее. В избирательных бюллетенях был предложен следующий вопрос: "Желаете ли Вы независимости или суверенитета?"27 Такой подход реализации принципа самоопределения поддерживается многими учеными. В современном международном праве при решении территориальньх проблем и политического статуса государства плебисцит (референдум) стал общепринятой формой демократического волеизъявления народа. Специалисты по данному вопросу неоднократно подтвержают юридическое значение плебисцита.

При выходе из состава какого-либо государства или полного отделения и создании самостоятельного государства плебисцит должен организовываться на самоопределяюшейся территории. Индийский профессор П.К. Мэнон подчеркивал роль народа и писал: “В современной практике государства с признанием права народа на самоопределение возникает вопрос возможности отделения, которое должно получить одобрение населения, проживающего на данной территории. Отделение без согласия народа может быть запрешено конституцией государств и, следовательно, быть недействительным, согласно ст. 46 Венской конвенции 1969 года о праве международного права"28. Ю.Г. Барсегов пишет: "Юридическое значение плебисцита захлючается в свободном выражении воли самоопределяющегося народа, в свободном определении судьбы населения и ее территорин... всякая по̆пытка насилием или несправедливостью влиять извне на результаты волеизъявления народа безусловно должна быть исключена"29.

Следуюшие данные свидетельствуют о воле народа Эритреи. В марте было зарегистрировано более 1,1 млн. эритрейцев, проживающих ках в Эритрее, так и за ее пределами: в Эритрее - 868074 , в Судане - 154136 , в Эфиопин - 66 022, в Саудовской Аравии - 43765 и 76000 в других странах $^{30}$. Голосование бьло осуществлено по следуюшим критериям: лица, родившиеся от отца или матери эритрейского происхождения, проживаюшие в Эритрее или за рубежом; лица, покннувшие страну вследствие войны и получившие гражданство другого государства; натурализированные лица до или после федерального периода; лица, адаптированные или по семейным связям имеющие право на участие в референдуме ${ }^{3 !}$. Референдум состоялся 23-25 апреля 1993 г. 1098015 человек голосовали за независимость, 1825 - против, 323 бюллетеня были признаны недействительными, то есть $99,8 \%$ проголосовали за независимость. 24 мая было объявлено Днем независимости Эритреи. 26 мая 1993 г. Совет Безопасности резолюцией 828/1993 рекомендовал принять Эритрею в члены ООН. 28 мая в соответствии с рекомендацией Совета Безопасности Генеральная Ассамблея приняла Эритрею в ООН как независимое государство. Она стала 182-м членом $\mathrm{OOH}^{32}$.

Вооруженная борьба за независимость в Эритрее повлияла на общую политическую картину в Эфиопии. К началу 1990-х годов сформировалось чувство национального самосознания. Такая обстановка в стране привлекла внимание некоторых специалистов, таких как Р.Н. Исмагилова. После сво- 
их исследований, проведенных ею непосредственно в Эфиопии в 1992 году, P.Н. Исмагилова дала такую характеристику ситуации: "Интеграционные этнокультурные процессы были значительно более интенсивными 10 15 лет тому назад. Ныне в связи с оживлением идей этнического самосознания и национализма почти всюду наблюдается рост интереса народов $\mathrm{K}$ собственным культурным ценностям и замедление интеграционных процессов, более того, в ряде случаев имеет место усиление процессов дезинтеграции" "33. При подготовке проекта новой Конституции большое внимание уделялось форме государственного устройства. Для многонациональной Эфиопии наиболее подходящей формой стала форма федерализма. Такая форма на началах федерализма предпочтительна для реализации принципа самоопределения наций и народов.

В действуюшей Конституции, вступившей в силу 21 августа 1995 г., провозглашено, что Эфиопия имеет федеративное устройство и демократическое управление, соответственно государство называется Федеративной Демократической Республикой Эфиопией (ст. 1). В соответствии с этим и ст. 39.2 и 39.3 территория Эфиопии делится на девять регионов (штатов) по национальному признаку. В ст. 39.1 говорится, что нация, народность и народ имеют право на самоопределение, включая отделение, без какихлибо ограничений. Право нации, народности или народа на самоопределение, включая отделение, реализуется соблюдением определенных демократических процедур. В п. 4 ст. 39 действующей Конституции Федеративной Демократической Республики Эфиопии установлено, что право нации, национальности и народов на самоопределение реализуется:

a) когда требование отделения поддерживается $\frac{1}{3}$ законодательных органов данной нации, национальности или данного народа;

б) когда федеральное правительство в течение трех лет после решения Совета требующей нации, национальности или требующего народа организует референдум;

в) когда требование отделения поддерживается большинством голосов на референдуме;

г) когда федеральное государство передает власть данной нации, народности или данному народу;

д) когда в установленном законом порядке осуществляется разделение имушества.

В настоящей работе были исследованы два пути реализации принципа самоопределения нацик: путь вооруженной борьбы до отделения (на примере Эритреи) и мирный путь. Почти все население страны стало жертвой этой вооруженной борьбы.

Социальный, политический и экономический кризисы продолжаются в течение 30 лет. Мы не исключаем роли мировой политики в разрешении данного конфликта. Прекращение конфронтации всех блоков и приближение к созданию всеобщей системы безопасности способствовало и прекращению огня в Эритрее.

Нельзя не оценить следуюшие слова Германа, политического деятеля США: “... мы подчеркивали, что для решения проблемы Эфиопии нет военного способа, а только мирные и политические переговоры доведут до стабильного мира. Этого подхода также придерживался Советский Союз" 34 . Как для Эфиопии, так и для других многоначиональных государств непри- 
годным путем является вооруженный путь. Провозглашенные права в ст. 1 , 5, 8, 16, 39 Конституцин Эфиопин 1995 года, непосредственно связанные с принципом самоопределения, являктся теми мерами, которые противостоят дезинтеграции и разжитанию национальной розни.

1 Французская буржуазная революиия 1778-1794. - М.: АН СССР, 1941. - С. 53.

2 Эмер де Ватель. Право народов. -М.: Юридическая литература, 1960. - С. 40.

${ }^{3}$ Аверьлнов КО.И. и др. Политический энциклопедический словарь. - M.: "Publishers", 1993.

- Старушенко Г.Б. Прнкиип самоопределения народов н наций во внешней политике Советского Corosa. - M., 1960. - C. 31-32.

The United Nations and Independence of Eritrea // The United Nations Blue Book Series. - 1996. - Vol. XII. - P. 14.

6 Бартницкий А. и Нечко Мантель. История Эфиопик. - М., 1976. - С. 267 (пер. с польск.).

'Так же. - С. 326-353; Громыко Ак. А. Африка. Энциклопедический справочник. - T. 2. - M., 1987. - C. 578.

Bavid Pool. Eritrican nationalism// Nationalism and Self Determination in the Horn of Africa. Ithaca Press. - L., 1983. - P. 175-181; The Birth of Nation Asmara. 1993. - P. 11-13.

9 The United Nations and Independence of Eritrea. - P. 12; Trevaskis G. K. N. Eritrea in transition 1941-1952. - Oxford University Press, 1960. - P. 127.

10 The United Nations and Independence of Eritrea. - P. 13.

$"$ Шараев В.И. Политические организацин Эфиопии. - М., 1993. - С. 33-36; Federal Ephiopia at cross-roads by the International Transparency Commission on Africa. - London - Stockholm - New York - Addis Abeba, 1995. - P. 194-200.

12 Patrick Gilkes. Centralism and the Ethiopian PMAG // I. M. Lewis. Nationalism and Self determination in the Horn of Africa. Ithaca press. - L., 1983. - P. 200.

13 Волкоеа Л.И. Нерушимость границ - новый принцип мехдународного права.-Ростов, 1987 , - С. $48-51$.

14 Taм жe. - C. 54.

15 Taм жe. - C. 61.

16 Patrick Gilkes. Op. cit. - P. 203.

17 Старушекко Г.Б. Не только тушить, но и предупреждать конфликты // Московский журнал международного права. - 1997. - № 1. - С. 41.

18 The Birth of Nation Asmara. - P. 22.

19 The Constitution of the Peoples Democratic Republic of Ethiopia. - Addis-Abeba, 1987.

20 Ленин В.И. Полн. со6р. соч. - Т. 25. - С. 64-77.

21 Черниченко C.B. Принцип самоопределения народов // Московский журнал мехдународного права. -1996. - № 4. - С. 5.

22 The United Nations and Independence of Eritrea. - P. 16; The Hom of Africa Bulletin. -1991. - № 5. - P. 3.

23 Ibidem.

24 Ibid. - P. 17.

25 Ibid. - P. 18.

26 The United Nations and Independence of Eritrea. - P. 14.

27 Ibid. - P. 4.

28 Menon P.K. State Territory // Revue de droit International de science diplomatiques et politiques (Geneva Suisse). - 1994. - N 1. - P. 19-29.

29 Барсегов Ю.Г. Территория в международном праве. - М.: Госориздат, 1958. - C. 123.

30 The United Nations and Independence of Eritrea. - P. 25. 
31 The Birth of Nation Asmara. - P. 41.

32 The United Nations and Independence of Eritrea. - P. 29.

33 Иснагилова Р.Н. и $\partial p$. Труды российских историко-этносоциологических экспедиций в Эфиопии в 1990-1992. - М.: Восточная литература, 1997. - С. 119.

34 The Horn of Africa Bulletin. - P. 2.

Статья поступила в редакцию в декабре 19972.

\section{МОЛОДЕЖНЫЕ КОНКУРСЫ}

Осенью 1997 года Российской ассоциацией содействия ООН (РАСООН) совместно с Программой развития ООН (ПРООН) в РФ и Московским государственным институтом международных отношений (Университетом) МИД РФ были объявлены три молодежных конхурса, посвященных знаменательной дате - 50-летню принятия Генеральной Ассамблеей ООН Всеобщей декларации прав человека.

Первый конкурс проводился с учашимися средних учебных заведений. Учашиеся, пожелавшие принять в нем участие, должны были налисать доклад на тему "ООН и права человека в России”. Второй конхурс был адресован студентам высших учебных заведений, которым была предложена более сложная тема для доклада: "Права человека и пути устойчивого развития в России". Третий конкурс приглашал молодежь в возрасте до 25 лет представить рисунок на тему прав человека размером не более $55 \times 55$ см при любой форме исполнения.

По итогам представленных дохладов авторнтетное мехдународное жюри отобрало лучшие работы и пригласило их авторов на второй тур конхурса - “хруглый стол", где кахдый должен был защитить устно свои идеи, изложенные в докладе.

Второй тур обоих конкурсов на написание докладов проходил 29 июня 1998 г. в ректорском конференц-зале МГИМО под руководством профессора А.В. Торкунова, председателя Российской ассоциации содействия ООН, ректора МТИМО(У). Авторитетное жюрн провело с участниками хонкурса два "круглых стола" (отдельно с учащимися средних школ и отдельно со студентами вузов) и подвело итоги обонх конкурсов.

Восемь учашихся средних школ - Яна Вебер из Новосибнрска, Крнстина Маркова из Красноармейска (Чувашская республика), Наталья Морозова из Самары, Ирина Урсегова из Екатеринбурга, Андрей Ручкин из Каңдалакши (Мурманская обл.), Евгения Рыбкина из Первоуральска (Свердловская обл.), Марина Титова из Кемерова и Лариса Чичкина из Калининграда - были прнзнаны лауреатами конкурса, и им были вручены соответствующие грамоты.

В соответствии с условиями хонкурса по результатам второго тура были определены три победителя, которые премированы поездкой в Нью-Йорк с посещением штаб-квартиры ООН; это Лариса Чичкина - 1-е место, Кристина Маркова - 2-е место и Андрей Ручкин - 3-е место. Дополнительно отмечена работа Натальи Морозовой. По итогам второго тура студенческого конкурса также определены три победителя; это, соответственно, Лия Карсахова из Самары, москвичка Анна Аставина и Муслим Тамазов из Нальчика. Им по условиям конкурса были вручены денежные премии. Что хасается третьего конкурса - на лучпий рисунок, то, $\mathrm{x}$ сожалению, работа с рнсунками оказалась для нас более сложной, чем работа с докладами. Мы впервые проводили конкурс рисун$\mathbf{x a , ~ и ~ и т о г и ~ п о ~ н е м у ~ п о к а ~ е ш е ~ н е ~ п о д в е д е н ы . ~}$

Хотелось бы отметить, что РАСООН в рамках совместной программы с Ассоциацией содействия ООН США проводит молодежные конкурсы на лучший доклад по одной из основных программ деятельности ООН прахтически ежегодно. Победители нашего хонхурса выезжали в США, где на балу в ООН, проводимом Америхансхой АСООН, подводятся итоги обоих конкурсов. В прошлом году в этой программе пронзошел сбой, но ведется работа по восстановлению доброй традиции.

В захлючение хочется выразить особую благодарность ПРООН и ее представителюрезиденту в России Филиппу Эльгуайелю за охазаннуго финансовую подцержку, что позволило реализовать эту программу.

Г.М. Ковритенко, первый заместитель председателя РАСООН 